Anders Perner Antoine Vieillard-Baron Jan Bakker

\title{
Fluid resuscitation in ICU patients: quo vadis?
}

Received: 26 May 2015

Accepted: 27 May 2015

Published online: 14 June 2015

(C) Springer-Verlag Berlin Heidelberg and ESICM 2015

This editorial discusses the article by Cecconi et al. available at: doi:10.1007/s00134-015-3850-x.

A. Perner $(\square)$

Department of Intensive Care, Copenhagen University Hospital, Copenhagen, Denmark

e-mail: anders.perner@regionh.dk

A. Vieillard-Baron

Intensive Care Unit, University Hospital Ambroise Paré,

APHP, Boulogne, France

\section{A. Vieillard-Baron}

INSERM U-1018, CESP, Team 5 EpReC, Renal

and Cardiovascular Epidemiology, University Versailles

St Quentin en Yvelines, Versailles, France

\section{J. Bakker}

Department of Intensive Care Adults, Erasmus MC University

Hospital, Rotterdam, The Netherlands

J. Bakker

Departamento de Medicina Intensiva, Pontificia Universidad

Católica de Chile, Santiago, Chile

\section{Introduction}

As reported by Cecconi et al. [1], the results of the point prevalence study FENICE on fluid challenge in 2213 patients admitted to one of 311 ICUs in 46 countries were quite clear. Practice was variable, the indications for fluid were mainly related to low blood pressure and no or simple haemodynamic parameters were used to guide fluid therapy. This raises a number of questions, the answers to which may guide us in the way forward in improving fluid resuscitation in ICU patients.

\section{Is hypotension a good indication for fluids?}

Maybe, but increase in blood pressure in response to fluid is certainly not a one-to-one relationship [2]. It depends on the very complex interaction between mean systemic filling pressure (does fluid actually increase stressed volume?), right- and left-sided heart function (does fluid significantly increase filling pressure and especially central venous pressure?) and arterial load [3-5]. Even if fluid will increase blood pressure, this may not be of relevance if tissue perfusion was not impaired in the first place [6]. Moreover, cardiac output may frequently increase after fluid administration without any change in blood pressure. Also there are obvious alternatives to the use of fluid for hypotension including vasopressors, inotropic agents, ceasing vasodilators and watchful waiting. Unfortunately there are no high-quality data supporting clinical decisions between these alternatives.

Presently, there are limited data on effects of fluids on the clinical markers of hypoperfusion (e.g. cerebral function, urinary output, mottling and lactate), on doseresponse relationships, time of action and safety. In addition, the three recent large trials on early goal-directed therapy showed no effect of a protocol resulting in more fluids given to patients with septic shock [7]. Our basic physiologic understanding may still be limited. Improving the understanding of the complex interactions of venous return and right and left heart function and bringing this to the bedside to improve care and finally outcome will prove to be a major task. The results of the FENICE study indicate that there is a large gap between even the simple modelling of the effects of a fluid bolus and clinical practice. This could be because we may have 
promoted a clinical culture where fear of not giving enough fluid to resolve hypoperfusion drives practice. At least the Surviving Sepsis Campaign guideline has promoted continued fluid therapy in spite of a very low level of evidence [8]. Clearly, the concept of optimizing tissue perfusion by maximizing stroke volume is context dependent [9] and requires more clinical studies [10].

\section{Why don't clinicians use advanced haemodynamic tools for fluid resuscitation?}

FENICE showed that only a minority used advanced haemodynamic tools, e.g. echocardiography was only used in $2 \%$ of fluid challenges in spite of promotion by experts [11].

The short answer to the question is that there is no high-quality evidence indicating improved patient outcome with the use of any of the advanced haemodynamic tools. This may be too much to ask for, but in the end therapeutic strategies guided by advanced tools should show improved care and/or outcome. However, some of the methods promoted have not been properly validated [12], at least not to the precision needed for guidance and re-assessment in the ICU setting. And for those parameters where there is proof of concept (e.g. dynamic changes in arterial waveform variables) [13], only a minority of patients may fulfil the prerequisites for these to be valid [14].

Learning from our "failures", it may be that the advanced tools are too complex in the average critical care setting and for the average clinician (too many prerequisites, too sophisticated, and too many different parameters and devices). Even the interpretation of values of the pulmonary artery catheter differed tremendously among intensivists [15]; why should this be any different for the new tools? If one adds the practical issues of implementing the use of advanced haemodynamic tools in the ICU 24/7, it may be understandable that clinicians and ICUs have not adopted them.

\section{What is a fluid challenge anyway?}

It is illustrative of the complexity that we have not properly defined what a fluid challenge or bolus is, nor what fluid resuscitation, expansion and therapy are; and when do we cross the line to fluid maintenance? Some definitions have been proposed, but we have never studied these [16]. For example in the FENICE study, fluid challenge was considered as giving up to $1000 \mathrm{~mL}$ of fluids, which may represent fluid expansion. Moreover, passive leg raising has been reported as a test to predict the response to a fluid challenge, whereas it may be considered as a true fluid challenge, although reversible, and initially well proposed to predict the response to fluid expansion.

\section{What should be done?}

The results of FENICE should be a wake-up call to all of us. We need to acknowledge that we hardly understand the basics of this complex area. We need to define or redefine fluid resuscitation, fluid challenge, fluid expansion, fluid bolus, fluid responsiveness and fluid therapy. Importantly, academia and industry need to do better in all aspects of research, because the internal and external validity has to be improved. And that goes for the basic, observational and interventional studies on fluid therapy. Some of the existing study databases may be utilized to pool data and improve existing estimates and form new hypotheses. The future will reveal if the "big data" approach may help in this field. And we need better validation studies of new methods and more trials with protocols based on the better of these methods (Table 1). Until we have more trial data, guideline committee and consensus panel members have to exhibit caution when issuing recommendations in areas with low-quality evidence. And the focus of our educational efforts should be reset based on the fact that clinical practice is very simple.

Table 1 Important research questions we need to answer to improve fluid resuscitation

What are the valid clinical, haemodynamic and biochemical markers of adequate tissue perfusion/oxygenation?

What are appropriate clinical/haemodynamic surrogates for these markers?

When is fluid unresponsiveness an appropriate clinical goal?

Is fluid resuscitation indicated when a clinical problem (hypotension or low urine output) co-exists with normal microcirculatory/ peripheral perfusion?

Is increased plasma-lactate always an indication for fluid resuscitation? If so what is the better cut-off value?

What is the dose-response relationship of fluid for microcirculatory perfusion, clinical hypoperfusion and outcome? And what are the side effects of different volume?

What are the safety limits in fluid resuscitation; may CVP, EVLW or oxygenation be used?

What are the appropriate outcome measures for trials in fluid resuscitation?

Which strategies improve patient outcome?

$C V P$ central venous pressure, EVLW extravascular lung water 


\section{Our proposals}

We propose that the intensive care societies and existing research networks and trial groups place fluid resuscitation at the top of the research agenda and promote collaborative efforts covering all aspects, including physiology, experimental medicine, clinical research, implementation sciences and industry. Different organisational frameworks will likely be needed to ensure the buy-in from all of the aforementioned; we trust the academic leadership of intensive care medicine to do what is right.

In any case, it will be a major task to improve fluid therapy in intensive care medicine and all aspects of our profession have to be involved.

Conflicts of interest None of the authors has relevant conflicts of interest.

\section{References}

1. Cecconi M, Hofer C, Teboul J-L, Pettila V, Wilkman E, Molnar Z, Della Rocca G, Aldecoa C, Artigas A, Jog S, Sander M, Spies C, Lefrant J-Y, De Backer D (2015) Fluid challenges in intensive care: the FENICE study. Intensive Care Med. doi:10.1007/s00134-015-3850-x

2. Magder SA (2014) The highs and lows of blood pressure: toward meaningful clinical targets in patients with shock. Crit Care Med 42:1241-1251

3. Cecconi M, Aya HD, Geisen M, Ebm C, Fletcher N, Grounds RM, Rhodes A (2013) Changes in the mean systemic filling pressure during a fluid challenge in postsurgical intensive care patients. Intensive Care Med 39:1299-1305

4. Berlin DA, Bakker J (2014) Understanding venous return. Intensive Care Med 40:1564-1566

5. Perner A, De Backer D (2014) Understanding hypovolaemia. Intensive Care Med 40(4):613-615

6. Leone M, Asfar P, Radermacher P, Vincent JL, Martin C (2015) Optimizing mean arterial pressure in septic shock: a critical reappraisal of the literature. Crit Care 19:101

7. Angus DC, Barnato AE, Bell D, Bellomo R, Chong CR, Coats TJ, Davies A, Delaney A, Harrison DA, Holdgate A, Howe B, Huang DT, Iwashyna T, Kellum JA, Peake SL, Pike F, Reade MC, Rowan KM, Singer M, Webb SA, Weissfeld LA, Yealy DM, Young JD (2015) A systematic review and meta-analysis of early goal-directed therapy for septic shock: the ARISE, ProCESS and ProMISe Investigators. Intensive Care Med. doi: 10.1007/s00134-015-3822-1
8. Dellinger RP, Levy MM, Rhodes A, Annane D, Gerlach H, Opal SM, Sevransky JE, Sprung CL, Douglas IS, Jaeschke R, Osborn TM, Nunnally ME, Townsend SR, Reinhart K, Kleinpell RM, Angus DC, Deutschman CS, Machado FR, Rubenfeld GD, Webb S, Beale RJ, Vincent JL, Moreno R (2013) Surviving Sepsis Campaign: international guidelines for management of severe sepsis and septic shock, 2012. Intensive Care Med 39:165-228

9. Pranskunas A, Koopmans M, Koetsier PM, Pilvinis V, Boerma EC (2013) Microcirculatory blood flow as a tool to select ICU patients eligible for fluid therapy. Intensive Care Med 39:612-619

10. Waechter J, Kumar A, Lapinsky SE, Marshall J, Dodek P, Arabi Y, Parrillo JE, Dellinger RP, Garland A (2014) Interaction between fluids and vasoactive agents on mortality in septic shock: a multicenter, observational study. Crit Care Med 42:2158-2168

11. Cecconi M, De Backer D, Antonelli M, Beale R, Bakker J, Hofer C, Jaeschke R, Mebazaa A, Pinsky MR, Teboul JL, Vincent JL, Rhodes A (2014) Consensus on circulatory shock and hemodynamic monitoring. Task force of the European Society of Intensive Care Medicine. Intensive Care Med 40:1795-1815
12. Wetterslev M, Haase N, Johansen RR, Perner A (2013) Predicting fluid responsiveness with transthoracic echocardiography is not yet evidence based. Acta Anaesthesiol Scand 57:692-697

13. Marik PE, Cavallazzi R, Vasu T, Hirani A (2009) Dynamic changes in arterial waveform derived variables and fluid responsiveness in mechanically ventilated patients: a systematic review of the literature. Crit Care Med 37:2642-2647

14. Mahjoub Y, Lejeune V, Muller L, Perbet S, Zieleskiewicz L, Bart F, Veber B, Paugam-Burtz C, Jaber S, Ayham A, Zogheib E, Lasocki S, Vieillard-Baron A, Quintard H, Joannes-Boyau O, Plantefeve G, Montravers P, Duperret S, Lakhdari M, Ammenouche N, Lorne E, Slama M, Dupont H (2014) Evaluation of pulse pressure variation validity criteria in critically ill patients: a prospective observational multicentre pointprevalence study. Br J Anaesth 112:681-685

15. Gnaegi A, Feihl F, Perret C (1997) Intensive care physicians' insufficient knowledge of right-heart catheterization at the bedside: time to act? Crit Care Med 25:213-220

16. Vincent JL, Weil MH (2006) Fluid challenge revisited. Crit Care Med 34:1333-1337 